\title{
Putting public health ethics into practice: a systematic framework
}

\author{
Georg Marckmann ${ }^{1}{ }^{*}$, Harald Schmidt ${ }^{2}$, Neema Sofaer $^{3}$ and Daniel Strech ${ }^{4}$ \\ 1 Institute of Ethics, History and Theory of Medicine, Ludwig-Maximilians-University Munich, Munich, Germany \\ ${ }^{2}$ Department of Medical Ethics and Health Policy, Center for Health Incentives and Behavioral Economics, Perelman School of Medicine, University of Pennsylvania, \\ Philadelphia, PA, USA \\ ${ }^{3}$ Centre of Medical Law and Ethics, The Dickson Poon School of Law, King's College London, London, UK \\ ${ }^{4}$ Institute for History, Ethics and Philosophy of Medicine, Centre for Ethics and Law in the Life Sciences (CELLS), Hannover Medical School, Hannover, Germany
}

\section{Edited by:}

Colette Joy Browning, Monash

University, Australia

Reviewed by:

Craig Fry, Victoria University, Australia Michael Peddecord, Quality Health

Analytics, USA

\section{${ }^{*}$ Correspondence:}

Georg Marckmann, Institute of Ethics, History and Theory of Medicine, Ludwig-Maximilians-University

Munich, Lessingstr. 2, D-80336

Munich, Germany

e-mail:marckmann@Imu.de
It is widely acknowledged that public health practice raises ethical issues that require a different approach than traditional biomedical ethics. Several frameworks for public health ethics (PHE) have been proposed; however, none of them provides a practice-oriented combination of the two necessary components: (1) a set of normative criteria based on an explicit ethical justification and (2) a structured methodological approach for applying the resulting normative criteria to concrete public health $(\mathrm{PH})$ issues. Building on prior work in the field and integrating valuable elements of other approaches to PHE, we present a systematic ethical framework that shall guide professionals in planning, conducting, and evaluating PH interventions. Based on a coherentist model of ethical justification, the proposed framework contains (1) an explicit normative foundation with five substantive criteria and seven procedural conditions to guarantee a fair decision process, and (2) a six-step methodological approach for applying the criteria and conditions to the practice of $\mathrm{PH}$ and health policy. The framework explicitly ties together ethical analysis and empirical evidence, thus striving for evidence-based PHE. It can provide normative guidance to those who analyze the ethical implications of $\mathrm{PH}$ practice including academic ethicists, health policy makers, health technology assessment bodies, and $\mathrm{PH}$ professionals. It will enable those who implement a PH intervention and those affected by it (i.e., the target population) to critically assess whether and how the required ethical considerations have been taken into account. Thereby, the framework can contribute to assuring the quality of ethical analysis in PH. Whether the presented framework will be able to achieve its goals has to be determined by evaluating its practical application.

Keywords: public health practice, health policy, ethics, program evaluation, ethical theory

\section{BACKGROUND}

Public health ethics (PHE) is a relatively new field of applied ethics, and is concerned with the moral implications of a diverse range of activities aiming to protect or improve population health. It is an interdisciplinary field that has to take into account both moral and factual considerations, in health policy and health sciences. $\mathrm{PH}$ practice differs considerably from medical practice: while the latter is primarily concerned with the health of individual patients, the former focuses on the health of populations. Protecting and promoting health and preventing diseases constitute the primary objectives of $\mathrm{PH}$ interventions, rather than treating sick individuals. Often, collective efforts of the community are required to achieve $\mathrm{PH}$ goals. Last but not least, it has been questioned whether the prevailing liberal approach to medical ethics is appropriate for the field of PH (1). It is therefore widely acknowledged that ethical inquiries in $\mathrm{PH}$ need a different approach than traditional biomedical ethics $(2,3)$.

To arrive at transparent, consistent, and justified results, ethical analysis in PH should follow a clearly defined methodological approach. Any framework for PHE thereby has to meet at least two fundamental requirements: (1) as a tool for normative inquiry, the framework must be based on an explicit ethical justification. This is a requirement of any ethical analysis: normative claims about what is morally acceptable must be justified by an underlying ethical theory or at least an explicit ethical approach. A transparent normative basis allows those who act upon the analysis (e.g., $\mathrm{PH}$ professionals) and those who are affected by the analysis (e.g., the target population) to assess the validity of the resulting claims. (2) A framework for PHE should provide practical guidance for the various people working within or related to the field of $\mathrm{PH}$. It therefore should include a methodological approach that relates the general normative considerations such as ethical norms, values, and principles and the available empirical evidence to concrete $\mathrm{PH}$ interventions, programs, or policies.

Several PHE frameworks have been developed over the last years [for some recent reviews, see Ref. (4-6)]. They differ with respect to their theoretical foundations, the selection of normative principles, and the practical guidance (6). So far, none of these frameworks has won universal approval as the go-to ethical framework in the field of $\mathrm{PH}$ - which may also be due to the 
fact that PHE is still a rather new field of inquiry. In addition, none provides a fully elaborated account of the two necessary ingredients of a PHE framework noted above, comprising both a clearly defined ethical foundation and a methodological approach. Some frameworks present a set of ethically relevant questions or points to consider without explicitly defining the normative basis, i.e., the underlying ethical principles and their justification $(2,7)$. Other frameworks comprise ethical principles for evaluating $\mathrm{PH}$ interventions, but fail to explain in more detail how these principles should be applied to evaluate particular interventions (3, 8). Childress et al. present a set of general moral considerations, i.e., an explicit normative foundation, and address some practical questions related to specifying and weighting the general moral considerations and resolving conflicts among them (9). While this certainly enhances the practical utility, it does not comprise a more comprehensive methodological approach that can guide - step by step - the ethical planning, conduct, and evaluation of $\mathrm{PH}$ policy.

In this article, we first outline what the preconditions and advantages of a systematic framework for PHE are. Building on and combining prior work in the field, we then present a systematic framework for addressing ethical issues in the field of $\mathrm{PH}$ that tries to satisfy both the foundational and methodological requirements. The framework comprises (1) an explicit normative foundation with five substantial ethical criteria and seven procedural conditions guiding a fair decision process, and (2) a six-step methodological approach for applying the ethical criteria and conditions. We have developed the framework primarily to provide practical guidance to those who want to analyze the ethical implications of $\mathrm{PH}$ practice including academic ethicists, health policy makers, health technology assessment bodies, and - last but not least $-\mathrm{PH}$ professionals.

\section{WHAT MAKES A FRAMEWORK FOR PHE SYSTEMATIC?}

In a PHE framework, both the selection of relevant ethical norms and principles and their application to a public heath program should be performed in a systematic way. The selection can be considered systematic if it follows a defined methodological approach to identify a comprehensive list of relevant ethical norms and principles that should be considered in every ethical analysis of $\mathrm{PH}$ practice [see e.g., Ref. $(3,8,9)$ ]. Any modification of the normative foundation by changing, adding, or omitting ethical considerations must be explicitly justified. Furthermore, the application of the ethical norms and principles to a certain $\mathrm{PH}$ program or issue can be considered systematic if it follows an explicitly defined process [see e.g., Ref. $(2,7,9)$ ]; again, any deviation from the procedure should be justified.

Using a systematic approach to PHE has several advantages:

(1) It reduces the risk that the evaluation neglects relevant ethical considerations or an important methodological step (10).

(2) It allows an explicit assessment of the process quality of a PHE analysis by checking whether the relevant norms and principles have been considered and whether the required methodological steps have been completed.

(3) It enables health policy makers, $\mathrm{PH}$ professionals, and members of the target population to assess whether the relevant norms and principles have been considered (11), whether and why they have been modified, and whether all methodological steps have been completed.

(4) It promotes a more explicit understanding among $\mathrm{PH}$ students and professionals what it means to assess the ethical implications of $\mathrm{PH}$ interventions.

Overall, a systematic framework to PHE has the potential to increase the quality of ethical analysis and reflection in the field of $\mathrm{PH}$.

\section{THE NORMATIVE FOUNDATIONS}

As it is one of the fundamental goals of PHE to provide normative guidance in the field of $\mathrm{PH}$, the framework must be grounded in an ethical theory or at least ethical approach that provides a justification of the selected principles and norms. However, there is intractable disagreement about which ethical theory is correct. Moral philosophy is characterized by a multitude of competing approaches that differ significantly in their justificatory strategies and PHE frameworks vary considerably with respect to their philosophical foundations (6). According to consequentialist theories, for example, the action or policy that has the best consequences is morally right (in utilitarianism the action that maximizes overall utility), irrespective of the resulting distribution. According to deontological theories, by contrast, moral obligations and individual rights determine which action is ethically mandated (e.g., to respect individual autonomy). As a consequence, the results of ethical analyses will vary considerably depending on the underlying ethical theory.

An alternative approach that explicitly acknowledges the complexity of normative orientations in modern pluralistic societies is the coherentist model of justification, which has been introduced as "reflective equilibrium" by John Rawls (12). In our view, it is also the most promising model for PHE (9). Unlike classical ethical theories, coherentism does not build on a single foundational moral principle, but rather starts with considered judgments, i.e., moral convictions and beliefs that we hold in our everyday life, and develops a coherent framework by specifying, testing, and revising them. The goal is a "reflective equilibrium" of theoretical assumptions, moral principles, and judgments about single cases. The four principles beneficence, non-maleficence, respect for autonomy, and justice, for example, are internationally recognized as a coherentistically justified set of moral principles for the field of biomedicine (13).

The principles that have been developed from considered judgments represent prima facie binding moral norms that must be followed unless they conflict with equally strong or stronger obligations. Moreover, they provide only general ethical orientations that require further content to give guidance in concrete cases. Thus, in application, the principles have to be specified and - in case of conflict - balanced (see below: methodological approach).

A coherentist model of justification has several advantages: despite unresolved foundational issues, it allows us to find consensus on the level of prima facie binding mid-level principles, since they build on our everyday moral convictions and are compatible with various ethical justifications. At the same time, it makes moral controversies more transparent, since they can be analyzed as conflicts between principles with different weights. Identifying 
precisely the type of ethical conflict is often the first step toward a solution.

Based on the coherentist model of justification, we have developed a normative foundation for PHE that contains five substantive ethical criteria (see Substantive Normative Criteria) and seven procedural conditions (see Procedural Conditions for a Fair Decision Process).

\section{SUBSTANTIVE NORMATIVE CRITERIA}

Table 1 presents the substantive normative criteria that should guide ethical analysis in $\mathrm{PH}$ based on a coherence approach of justification (see above). They are linked to the specific characteristics of the field of $\mathrm{PH}$, thereby taking into account that $\mathrm{PH}$ focuses on populations rather than individuals, works preventively rather than curatively, and usually requires action at the population rather than the individual level (1). Many ethical principles and considerations relevant for $\mathrm{PH}$ have already been elaborated over the last several years [cf. the reviews Ref. (4-6)]. As "considered judgments" about what is morally important in $\mathrm{PH}$, they constitute the basic ingredients of our coherentist approach and are reflected - explicitly or implicitly - in our list of normative criteria. They are justified by more basic ethical principles including maximizing health benefits, preventing harm, respecting autonomy, or promoting justice. The order of the criteria is determined by the sequence of their application. First of all, the benefit of the intervention has to be established. Without an expected benefit, the intervention should not be implemented and there is no need to apply the other criteria. After assessing expected benefits and potential harms of the intervention, implications on individual autonomy, distributive justice, and efficiency can be evaluated. It is important to realize that this set of criteria constitutes only the starting point of any ethical analysis. Before applying the criteria, evaluators have to assess whether all criteria are relevant to the $\mathrm{PH}$ intervention or policy decision, whether further criteria have to be taken into consideration and whether the criteria require further specification for the application domain.

\section{What are the expected health benefits of the intervention for the target population?}

An ethical evaluation of a PH intervention must start with assessing its expected benefit. This requires defining the goals of the intervention with the range of expected effects. These can be surrogate endpoints, e.g., the identification of cancer in its early stages or more patient-oriented endpoints, e.g., lowering the cancer-specific mortality rate. The magnitude and likelihood of the effect should be quantified (e.g., reduction of the morality rate for breast cancer from $4 / 1000$ to $3 / 1000$ in the next 10 years through mammography screening for healthy 30 -year-old women) (14). In addition, the validity of the available evidence is relevant. Are the underlying studies randomized-controlled trials or retrospective cohort studies? How adequately have the studies been implemented and published [e.g., selective reporting of study findings on the healthrelated effects of smoking (15))? Besides internal validity (the credibility of the results for the study sample), the external validity of the demonstrated effect is also relevant. The external validity concerns the credibility of the results outside of the study sample and thus indicates how generalizable the results are. Only if a relevant
Table 1 | Substantive normative criteria for ethical analysis in public health.

Normative criteria

1 Expected health benefits for the target population

- Range of expected effects (endpoints)

- Magnitude and likelihood of each effect

- Strength of evidence of each effect

- Public health (practical) relevance of effects

- Incremental benefit compared to alternative interventions

2 Potential harm and burdens

- Range of potential negative effects (endpoints)

- Magnitude and likelihood of each negative effect

- Strength of evidence for each negative effect

- Public health (practical) relevance of the negative effects

- Burdens and harms compared to alternative interventions

3 Impact on autonomy

- Health-related empowerment (e.g., improved health literacy)

- Respect for individual autonomous choice

(e.g., possibility of informed consent, least restrictive means)

- Protection of privacy and confidentiality (e.g., data protection)

4 Impact on equity

- Access to the public health intervention

- Distribution of the intervention's benefits, burdens and risks

- Impact on health disparities

- Need for compensation?

5 Expected efficiency

- Incremental cost-benefit/cost-effectiveness ratio

- Strength of evidence for expected efficiency

health-related effect can be demonstrated or justified on the basis of sufficiently valid study results, does it make sense to speak of "benefits" of a certain PH intervention. The intervention-specific, health-related benefit should be higher than the potential benefits of alternative interventions, thereby providing an additional benefit for the target population.

An expected benefit can seem plausible even if the underlying evidence is not of the highest desirable internal and external validity. In this case, it is necessary to explicitly state the reasons for the lack of suitable data and the arguments why it nevertheless seems appropriate to implement the intervention. This transparency is a necessary prerequisite for dealing appropriately with the frequently uncertain demonstration of benefits in the field of $\mathrm{PH}$ $(16,17)$.

The necessity to review alternative $\mathrm{PH}$ interventions to achieve the same goal is not just an imperative of instrumental rationality and the principle of benefit maximization, but also allows us to identify any alternatives that might be ethically less problematic e.g., by being less restrictive on individual autonomy (see third principle).

\section{What are the potential burdens and harms of the intervention?}

Oftentimes, beneficial PH interventions are associated with social and health risks and burdens (e.g., false positive findings with consecutive unnecessary interventions in the case of cancer screening). For this reason, it is important to assess not only potential benefits 
but also potential harms. Potential harm should be assessed for those directly and indirectly affected and be compared with the expected benefit for the target population to determine the netbenefit. Analogous to the expected benefit, the magnitude, likelihood, and scientific validity of the potential harm need to be assessed [cf. Ref. (18)]. It is one of the central goals of the ethical assessment to recommend suitable measures for reducing the often unavoidable - risk of harm for the individual as much as possible.

In summary, (i) the practical relevance of the different endpoints (e.g., decreased cancer-related mortality vs. improved early detection of cancer), (ii) the magnitude and likelihood of the effects, and (iii) the scientific validity of the demonstrated effects plays a crucial role in the ethical evaluation of a $\mathrm{PH}$ intervention. The controversy among experts on the benefits and harms of mammography screening exemplifies how differently these three aspects can be assessed in a single intervention (19) and how these differences affect $\mathrm{PH}$ decision making.

After balancing benefits and harms of the intervention, we can determine whether overall there is a "net-benefit" or "net-harm." Only if there is a (sufficiently valid) actual or expected net-benefit does it make sense to continue the ethical evaluation.

\section{How does the intervention affect the autonomy of the individuals in the target population?}

The ethical principle respect for autonomy is relevant to PHE in two ways. First, PH interventions can and should (if possible) improve the health literacy and competence of the target population (20-22). For this purpose, it is necessary to provide, among other things, high-quality information about the type of intervention and its potential benefits and harm, adapted to the needs of people with different knowledge, capabilities and ways of accessing information $(23,24)$. Second, in light of the usually unavoidable burdens and risks, individuals should generally be able to decide themselves about their participation in a certain $\mathrm{PH}$ program after being sufficiently informed (informed consent). If individual informed consent to participation is not possible (e.g., tab water fluoridation), there should be a democratically legitimate public decision process about the implementation of the $\mathrm{PH}$ intervention.

If certain PH goals can only be achieved effectively by influencing or even restricting individual freedom of choice (e.g., incentive systems, legal obligations, or quarantine interventions), this requires a special justification. In particular, it has to be demonstrated that the $\mathrm{PH}$ goal cannot be achieved with a less restrictive or less manipulative intervention (25). As a general rule, restrictions should be minimized (9). For example, before legally mandating a $\mathrm{PH}$ intervention, there should be an attempt to achieve sufficient participation by non-coercive incentives. The fact that a less restrictive intervention might forfeit a potential health benefit for the population is not per se an argument for more restrictive interventions. The expected health benefit rather has to be balanced against the potential social harm (restriction of freedom, protection of privacy, or stigmatization).

\section{Impact on equity: how are benefits and burden distributed?}

Public health interventions often have an impact on the distribution of health outcomes and therefore the opportunities that citizens are offered in a society (26). For reasons of equity, therefore, all people who might benefit should have equal access to a given $\mathrm{PH}$ intervention. Both financial and non-financial barriers to access have to be taken into account. In addition, the distribution of potential benefits and harm has to be examined. $\mathrm{PH}$ interventions should contribute to reducing existing health inequalities. For example, interventions can be tailored to the needs of health-disadvantaged groups (while avoiding possible negative social consequences like stigmatization).

When $\mathrm{PH}$ interventions accept a potential harm for certain subgroups to achieve a significant expected benefit for another subgroup, strategies to compensate for these risks have to be considered for the sake of compensatory justice. For example, people placed under quarantine need to be given appropriate psychological support and their captivity should be alleviated as well as possible beyond the regular standard of care in hospitals. Another example concerns health professionals exposed to an increased risk of infection by their patient contact during a pandemic (e.g., SARS): they should be compensated by an independent fund to cover their illness or absence from work (27).

\section{Expected efficiency: what are the costs and opportunity costs of the intervention?}

In the light of limited public resources, the efficiency of a $\mathrm{PH}$ intervention has to be assessed. This requires determining the incremental cost-benefit ratio, i.e., the ratio between additional costs and additional benefit compared to alternative interventions (if available). The type of benefit and harm entering into the netbenefit of the $\mathrm{PH}$ interventions has to be explicitly defined. As with the potential benefit and harm, the internal and external validity of the efficiency assessment have to be evaluated. Determining the incremental cost-benefit ratio presupposes reviewing the alternative (if any) strategies to achieve the same $\mathrm{PH}$ goals.

\section{PROCEDURAL CONDITIONS FOR A FAIR DECISION PROCESS}

Since PH interventions have an impact on the well-being and autonomy of individuals and often require collective efforts, they should be implemented by a legitimate decision-making authority within a fair process. Even reasonable and fair-minded people often come to different conclusions in the face of complex moral deliberations. Among other things, this is due to the fact that many evaluations - e.g., of health-related benefits - can only be made on the basis of substantial visions of a good or fulfilled life. How can we make legitimate decisions under these conditions of moral controversy? Norman Daniels argues that we have to supplement the general substantive principles of justice with a fair decision process that "holds decision makers accountable for the reasonableness" of their decisions (26). "Accountability for reasonableness" requires four procedural conditions of fairness: transparency (publicity condition), reasonable explanation (relevance condition), openness for revision (revision and appeals condition), and the regulation of adherence to the other three conditions (regulative condition) (26). We suggest adding consistency, participation, and managing conflicts of interest (28-30), so that any ethical analysis of $\mathrm{PH}$ interventions has to assess how far the seven conditions for a fair decision process described in Table 2 are met. Further conceptual research is necessary to develop quality criteria for the practical 
Table 2 | Conditions of a fair decision process.

\section{Conditions for a fair decision process}

1 Transparency Decision process including database and underlying normative assumptions should be transparent and public

2 Consistency

Application of the same principles, criteria and rules across different public health interventions $\rightarrow$ equal treatment of different populations

3 Justification

Decisions should be based on relevant reasons, i.e., based on the normative criteria for PHE (Table 1)

4 Participation

Populations affected by the $\mathrm{PH}$ intervention should be able to participate in the decision about the implementation

5 Managing conflicts of Decisions about PH interventions should be organized interest so as to minimize any existing and manage any

\section{Openness} for revision remaining conflicts of interests of decision makers

Implementations of $\mathrm{PH}$ interventions should be open for revision (e.g., if data basis changes or certain aspects have been neglected)

7 Regulation

Voluntary or legal regulation should guarantee that these conditions for a fair decision process are met

implementation of the seven conditions (e.g., what determines a high quality, reasonable explanation?). Further empirical research is necessary to evaluate the feasibility as well as the intended and unintended effects of the seven conditions (31). The results may help to determine more specific guidelines on the adequate implementation of the seven procedural conditions in the practice of $\mathrm{PH}$ (32-34).

\section{METHODOLOGICAL APPROACH TO PHE}

After having laid out substantive ethical criteria and conditions for a fair decision process, we now present a step-by-step methodological approach that shall guide the ethical evaluation of a given $\mathrm{PH}$ intervention in the different phases of its development, implementation, and evaluation.

\section{Description of the public health intervention}

Any ethical analysis must start with a thorough characterization of the PH intervention, the context in which it will be applied, and possible alternative interventions to achieve the $\mathrm{PH}$ goal that might minimize potential negative impact on $\mathrm{PH}$, individual autonomy, equity, or efficiency.

\section{Specification and modification of the normative criteria}

After describing the $\mathrm{PH}$ intervention, the normative basis of the evaluation needs a critical review: do the normative criteria (cf. Table 1) require further specification or even supplementation for the $\mathrm{PH}$ intervention? The practical relevance of each principle should be clarified, starting with a concrete statement of the content and scope of the principle for the $\mathrm{PH}$ intervention at hand. Different policy makers or evaluators may arrive at different specifications with potentially different results in the analysis. While this cannot be eliminated completely, using this explicit framework at least requires the evaluators to explicitly define and justify the specifications so that the underlying sources of disagreement become transparent - and thereby open to revision.

In practice, the five normative criteria (Table 1) are often given unequal consideration. For example, an investigation might focus more on balancing expected benefits (criterion 1) with the restrictions of autonomy (criterion 3), while neglecting equity implications (criterion 4). In the ethical debates on mammography screening, equity is often overlooked, despite the screening's high costs (35) and the well-known disparities in breast cancer outcomes between racial and ethnic groups (36). Similarly, many criticisms of national pandemic plans make some effort to apply criteria $1-3$ but do not explicitly consider criteria $4-6(37,38)$.

\section{Evaluation of the public health intervention using the specified criteria}

In the third step, each of the specified normative criteria is used to evaluate the $\mathrm{PH}$ intervention. The evaluators must ask, for example: what are the expected benefits of the intervention? What are the program's implications for the autonomy of members of the target population? A step-by-step assessment can reveal currently unresolved controversies and identify the need for further conceptual or empirical studies.

\section{Synthesis: overall evaluation of the public health intervention}

The fourth step requires compiling each assessment from the previous step into an overall evaluation of the $\mathrm{PH}$ intervention. This involves identifying conflicts between the criteria and balancing the conflicting ethical obligations. Balancing requires finding convincing reasons why one criterion or the other should prevail. Being explicit about the reasons that determine the relative weights of the conflicting criteria creates transparency and allows a revision of the balancing by challenging the underlying reasons. For example, there might be good reasons to doubt the validity of the information considered in a particular case or competing information might be available.

The balancing of conflicting ethical obligations shall be illustrated by two examples:

Example 1: in considering a quarantine of a tuberculosis patient, we have to balance respect for autonomy (criterion 3) and protecting others from the risk of a transmitted tuberculosis infection (here: criterion 1). The severity and high likelihood of the anticipated harm to others could be a good reason to assign more weight to protecting others than to the freedom of the infected patient.

Example 2: despite empirical evidence indicating that influenza vaccination of health care personnel (HCP) in long-term care facilities may reduce the residents' all-cause mortality and morbidity (39), vaccination rates remain rather low thus raising the question whether mandatory vaccination policies should be implemented. Here, the ethical conflict lies between the expected benefits for the long-term care residents (criterion 1) on the one side and the potential burdens and risks by the influenza vaccination for the HCP (criterion 2) and the HCP's restriction of 
freedom of choice (criterion 3) on the other side. To balance the conflicting criteria, we have to assess the relative weight of the arguments (40): the benefit for the target population - 5 prevented deaths per 100 residents in one study (41) - seems to be rather large compared to the burdens and risks for the HCP due to the influenza vaccination and the restriction of freedom of choice. However, the available studies could not prove a significant effect on the primary outcome, i.e., a reduction of the mortality and morbidity caused by a laboratory proven influenza infection (39), which somewhat weakens the beneficence-based arguments in favor of a mandatory vaccination policy (for more details see Ref. (42)].

The latter example points to another important ethical consideration in the synthesis: before implementing a $\mathrm{PH}$ intervention that involves a conflict between the normative criteria, it is important to carefully look for alternative strategies to achieve the $\mathrm{PH}$ goal that are ethically less challenging. For example, if a PH intervention is particularly effective but requires a significant restriction of individual autonomy, it should be investigated whether a less restrictive intervention could lead to satisfactory results, perhaps at the price of a somewhat reduced effectiveness. Before implementing a mandatory influenza vaccination policy for $\mathrm{HCP}$, for example, it has to be shown that information or incentive based programs have failed to reach sufficiently high vaccination rates to effectively protect the elderly residents $(42,43)$, especially in light of the somewhat limited evidence on the vaccination's specific effect on mortality and morbidity in the target group.

\section{Generating recommendations}

In most cases, the overall ethical evaluation will not result in a clear-cut rejection or endorsement of the $\mathrm{PH}$ intervention, but rather in a stronger or weaker recommendation, for example, to implement or - in the cases of a negative evaluation - forgo the intervention (see Table 3). Rather, it will identify various aspects and conflicts that have to be considered from an ethical perspective. In these cases, the evaluation should be translated into recommendations on how to maximize the intervention's expected benefits and minimize the expected costs (e.g., expected social and health-related harms, restrictions of autonomy). For example, the recommendation concerning influenza vaccination of HCP could be the following: before implementing mandatory programs, further evidence on the vaccination's specific effects and the proof that information and incentive based programs have failed are required (42). And if mandatory vaccination policies are considered, the HCP should be involved in the decision-making process (cf. criteria 4, Table 2).

\section{Monitoring}

After successful implementation, any $\mathrm{PH}$ program should be followed-up and monitored in regular intervals to assess (1) whether the ethical evaluation was adequate, (2) whether there are new ethical issues arising, and (3) whether the recommendations are followed and whether they are effective in assuring an ethically appropriate execution of the $\mathrm{PH}$ program. For example, vaccination prioritization plans for a pandemic with "magnitude of risk" as one prioritization criterion should be re-evaluated when
Table 3 | Methodological approach for putting PHE into practice.

\begin{tabular}{|c|c|c|}
\hline & Step & Task \\
\hline 1 & Description & $\begin{array}{l}\text { Describe the goals, methods, target population, } \\
\text { etc., of the } \mathrm{PH} \text { program }\end{array}$ \\
\hline 2 & Specification & $\begin{array}{l}\text { Specify or supplement (if necessary) the five } \\
\text { normative criteria for the } \mathrm{PH} \text { intervention }\end{array}$ \\
\hline 3 & Evaluation & $\begin{array}{l}\text { Evaluate the PH intervention based on each of } \\
\text { the } 5 \text { normative criteria (cf. Table 2) }\end{array}$ \\
\hline 4 & Synthesis & $\begin{array}{l}\text { Balance and integrate the } 5 \text { single evaluations of } \\
\text { step } 3 \text { to arrive at an overall evaluation of the } \mathrm{PH} \\
\text { intervention }\end{array}$ \\
\hline 5 & Recommendation & $\begin{array}{l}\text { Develop recommendations for the design, } \\
\text { implementation, or modification of the } \mathrm{PH} \\
\text { intervention }\end{array}$ \\
\hline 6 & Monitoring & $\begin{array}{l}\text { Monitor and re-evaluate the ethical implications } \\
\text { in regular time intervals }\end{array}$ \\
\hline
\end{tabular}

empirical data about the "real" risks of the pandemic are available. Or: mandatory vaccination policies should be evaluated whether they really have an additional benefit on the mortality and morbidity of elderly long-term care residents compared to voluntary programs. Furthermore, HCP's attitudes toward the mandatory policy should be investigated by socio-empirical studies to assess how the HCP feels about the infringement of their autonomy.

Another example for the demand of monitoring the follow up and the effects of ethical recommendations is the following: there is a broad consent that mammography screening becomes more ethical if participants are adequately informed about potential benefits and harms of the screening procedure itself. The ethical analysis, however, should not stop with the recommendation to inform adequately but should be bound to the necessity of quality assessments with respect to the information process and its results $(24,44)$.

\section{LIMITATIONS}

We have developed the framework primarily to provide practical guidance. The transparent, systematic approach will enable those who implement a $\mathrm{PH}$ intervention and those affected by it (i.e., the target population) to critically assess whether and how the required ethical considerations have been taken into account. Thereby, the framework can contribute to assuring the quality of ethical analysis in PH. The results of the evaluation can then be the basis for political decisions on several levels in the health care system and society about the implementation of PH interventions. While it is not the primary goal of the framework to provide guidance for these political processes, some of the ethical requirements will also apply: especially, the conditions of a fair decision process (cf. Table 2) should also be met in the political sphere of decision making - which currently is often not the case.

Whether the presented framework will be able to achieve its goals has to be determined by practical application: are all necessary normative considerations concerning substantive justification and procedural fairness included in the framework? Does the 
methodological approach provide a useful tool for evaluators of $\mathrm{PH}$ practice? Applying the framework to further examples of $\mathrm{PH}$ interventions will shed more light on its strengths and weaknesses. The framework itself requires critical monitoring by scholars and practitioners in the field of $\mathrm{PH}$.

\section{SUMMARY}

There is an increasing need for assessing the ethical implications of $\mathrm{PH}$ practice. While several approaches have been published over the last decade, none of them give a complete account of both the normative foundation and the methodological approach. Based on a coherentist model of justification, we set out here a systematic framework for ethical analysis in PH that includes (1) an explicit normative foundation with five substantial criteria and seven procedural conditions and (2) a six-step methodological approach for applying the normative considerations to concrete $\mathrm{PH}$ interventions. Thereby, the framework explicitly ties together ethical analysis and empirical evidence: ethical consideration is not merely an "add-on" to empirically data. Rather, normative questions about the effectiveness, benefits, or harms of a PH intervention can only be answered by reference to the evidence from empirical studies. In this respect, the framework strives for evidence-based PHE.

\section{AUTHOR CONTRIBUTIONS}

GM and DS conceived of the manuscript, GM, HS, NS, and DS all made substantial contributions to the intellectual content and participated in drafting and revising the manuscript. They all read and approved the final manuscript and agree to be accountable to all aspects of the work.

\section{REFERENCES}

1. Dawson A. Resetting the parameters. Public health as the foundation for public health ethics. In: Dawson A, editor. Public Health Ethics. Cambridge: Cambridge University Press (2011). p. 1-19.

2. Kass NE. An ethics framework for public health. Am J Public Health (2001) 91(11):1776-82. doi:10.2105/AJPH.91.11.1776

3. Upshur RE. Principles for the justification of public health intervention. Can J Public Health (2002) 93(2):101-3. Available from: http://journal.cpha.ca/index. php/cjph/article/view/217/217

4. Petrini C. Theoretical models and operational frameworks in public health ethics. Int J Environ Res Public Health (2010) 7(1):189-202. doi:10.3390/ ijerph7010189

5. ten Have M, de Beaufort ID, Mackenbach JP, van der Heide A. An overview of ethical frameworks in public health: can they be supportive in the evaluation of programs to prevent overweight? BMC Public Health (2010) 10:638. doi:10.1186/1471-2458-10-638

6. Lee LM. Public health ethics theory: review and path to convergence. J Law Med Ethics (2012) 40(1):85-98. doi:10.1111/j.1748-720X.2012.00648.x

7. Jennings B, Kahn J, Mastroianni A, Parker LS, editors. Ethics and Public Health: Model Curriculum. Rockville, MD: Health Resources and Services Administration (HRSA); Washington, DC: Association of Schools of Public Health (ASPH) (2003).

8. Roberts MJ, Reich MR. Ethical analysis in public health. Lancet (2002) 359(9311):1055-9. doi:10.1016/S0140-6736(02)08097-2

9. Childress JF, Faden RR, Gaare RD, Gostin LO, Kahn J, Bonnie RJ, et al. Public health ethics: mapping the terrain. J Law Med Ethics (2002) 30(2):170-8. doi:10.1111/j.1748-720X.2002.tb00384.x

10. Gawande A. The Checklist Manifesto: How to Get Things Right. New York: Metropolitan Books (2009).

11. Sofaer N, Strech D. The need for systematic reviews of reasons. Bioethics (2012) 26(6):315-28. doi:10.1111/j.1467-8519.2011.01858.x

12. Rawls J. A Theory of Justice. Cambridge, MA: Harvard University Press (1971).
13. Beauchamp TL, Childress JF. Principles of Biomedical Ethics. 7th ed. New York: Oxford University Press (2013).

14. Humphrey LL, Helfand M, Chan BK, Woolf SH. Breast cancer screening: a summary of the evidence for the U.S. Preventive Services Task Force. Ann Intern Med (2002) 137(5 Pt 1):347-60. doi:10.7326/0003-4819-137-5_Part_1-20020903000012

15. Gruning T, Gilmore AB, McKee M. Tobacco industry influence on science and scientists in Germany. Am J Public Health (2006) 96(1):20-32. doi:10.2105/ AJPH.2004.061507

16. Kelly M, Morgan A, Ellis S, Younger T, Huntley J, Swann C. Evidence based public health: a review of the experience of the National Institute of Health and Clinical Excellence (NICE) of developing public health guidance in England. Soc Sci Med (2010) 71(6):1056-62. doi:10.1016/j.socscimed.2010.06.032

17. Brownson RC, Chriqui JF, Stamatakis KA. Understanding evidence-based public health policy. Am J Public Health (2009) 99(9):1576-83. doi:10.2105/AJPH. 2008.156224

18. Rid A, Wendler D. A framework for risk-benefit evaluations in biomedical research. Kennedy Inst Ethics J (2011) 21(2):141-79. doi:10.1353/ken.2011.0007

19. Strech D, Tilburt J. Value judgments in the analysis and synthesis of evidence. $J$ Clin Epidemiol (2008) 61(6):521-4. doi:10.1016/j.jclinepi.2008.01.001

20. Institute of Medicine. Health Literacy: A Prescription to End Confusion. Washington, DC: Institute of Medicine (IOM) Committee on Health Literacy (2004).

21. Kickbusch IS. Health literacy: addressing the health and education divide. Health Promot Int (2001) 16(3):289-97. doi:10.1093/heapro/16.3.289

22. Nutbeam D. The evolving concept of health literacy. Soc Sci Med (2008) 67(12):2072-8. doi:10.1016/j.socscimed.2008.09.050

23. Gigerenzer G, Mata J, Frank R. Public knowledge of benefits of breast and prostate cancer screening in Europe. J Natl Cancer Inst (2009) 101(17):1216-20. doi:10.1093/jnci/djp237

24. Wegwarth O, Gigerenzer G. "There is nothing to worry about": gynecologists' counseling on mammography. Patient Educ Couns (2011) 84(2):251-6. doi:10.1016/j.pec.2010.07.025

25. van Delden JJ, Ashcroft R, Dawson A, Marckmann G, Upshur R, Verweij MF. The ethics of mandatory vaccination against influenza for health care workers. Vaccine (2008) 26(44):5562-6. doi:10.1016/j.vaccine.2008.08.002

26. Daniels N. Just Health: Meeting Health Needs Fairly. Cambridge: Cambridge University Press (2008).

27. Singer PA, Benatar SR, Bernstein M, Daar AS, Dickens BM, MacRae SK, et al. Ethics and SARS: lessons from Toronto. BMJ (2003) 327(7427):1342-4. doi:10.1136/bmj.327.7427.1342

28. Emanuel EJ. Justice and managed care. Four principles for the just allocation of health care resources. Hastings Cent Rep (2000) 30(3):8-16. doi:10.2307/ 3528040

29. Marckmann G, Strech D. Konzeptionelle grundlagen einer public health ethik. In: Strech D, Marckmann G, editors. Public Health Ethik. Berlin: LIT Verlag (2010). p. 43-65.

30. Institute of Medicine. Conflicts of Interest in Medical Research, Education, and Practice. Washington, DC: National Academies Press, Institute of Medicine (IOM) (2009).

31. Kreis J, Schmidt H. Public engagement in health technology assessment and coverage decisions: a study of experiences in France, Germany, and the United Kingdom. J Health Polit Policy Law (2013) 38(1):89-122. doi:10.1215/036168781898812

32. Abelson J, Forest PG, Eyles J, Smith P, Martin E, Gauvin FP. Deliberations about deliberative methods: issues in the design and evaluation of public participation processes. Soc Sci Med (2003) 57(2):239-51. doi:10.1016/S0277-9536(02) 00343-X

33. Strech D, Knuppel H. How to evaluate conflict of interest policies. Am J Bioeth (2011) 11(1):37-9. doi:10.1080/15265161.2011.534956

34. De Vries R, Stanczyk A, Wall IF, Uhlmann R, Damschroder LJ, Kim SY. Assessing the quality of democratic deliberation: a case study of public deliberation on the ethics of surrogate consent for research. Soc Sci Med (2010) 70(12):1896-903. doi:10.1016/j.socscimed.2010.02.031

35. Truog RD. Screening mammography and the "r" word. N Engl J Med (2009) 361(26):2501-3. doi:10.1056/NEJMp0911447

36. Smith-Bindman R, Miglioretti DL, Lurie N, Abraham L, Barbash RB, Strzelczyk J, et al. Does utilization of screening mammography explain racial and ethnic differences in breast cancer? Ann Intern Med (2006) 144(8):541-53. doi:10.7326/0003-4819-144-8-200604180-00004 
37. Thompson AK, Faith K, Gibson JL, Upshur RE. Pandemic influenza preparedness: an ethical framework to guide decision-making. BMC Med Ethics (2006) 7:E12. doi:10.1186/1472-6939-7-12

38. World Health Organization. Ethical Considerations in Developing a Public Health Response to Pandemic Influenza. Geneva: World Health Organization (2007).

39. Thomas RE, Jefferson T, Lasserson TJ. Influenza vaccination for healthcare workers who work with the elderly: systematic review. Vaccine (2010) 29(2):344-56. doi:10.1016/j.vaccine.2010.09.085

40. Marckmann G, Sanktjohanser AM, Wicker S. How the weight of the ethical arguments depends on the empirical "facts". Am J Bioeth (2013) 13(9):53-5. doi:10.1080/15265161.2013.813605

41. Hayward AC, Harling R, Wetten S, Johnson AM, Munro S, Smedley J, et al. Effectiveness of an influenza vaccine programme for care home staff to prevent death, morbidity, and health service use among residents: cluster randomised controlled trial. BMJ (2006) 333(7581):1241. doi:10.1136/bmj. 39010.581354 .55

42. Marckmann G, van Delden JJM, Sanktjohanser AM, Wicker S. Influenza vaccination for health care personnel in long-term care homes: what restrictions of individual freedom of choice are morally justifiable? In: Strech D, Hirschberg I, Marckmann G, editors. Ethics in Public Health and Health Policy Concepts, Methods, Case Studies. Dordrecht: Springer (2013). p. 235-50.

43. Ottenberg AL, Wu JT, Poland GA, Jacobson RM, Koenig BA, Tilburt JC. Vaccinating health care workers against influenza: the ethical and legal rationale for a mandate. Am J Public Health (2011) 101(2):212-6. doi:10.2105/AJPH.2009. 190751

44. Steckelberg A, Hulfenhaus C, Haastert B, Muhlhauser I. Effect of evidence based risk information on "informed choice" in colorectal cancer screening: randomised controlled trial. BMJ (2011) 342:d3193. doi:10.1136/bmj.d3193

Conflict of Interest Statement: The authors declare that the research was conducted in the absence of any commercial or financial relationships that could be construed as a potential conflict of interest.

Received: 07 November 2014; paper pending published: 07 December 2014; accepted: 25 January 2015; published online: 06 February 2015.

Citation: Marckmann G, Schmidt H, Sofaer N and Strech D (2015) Putting public health ethics into practice: a systematic framework. Front. Public Health 3:23. doi: 10.3389/fpubh.2015.00023

This article was submitted to Public Health Education and Promotion, a section of the journal Frontiers in Public Health.

Copyright (c) 2015 Marckmann, Schmidt, Sofaer and Strech. This is an open-access article distributed under the terms of the Creative Commons Attribution License (CC $B Y)$. The use, distribution or reproduction in other forums is permitted, provided the original author(s) or licensor are credited and that the original publication in this journal is cited, in accordance with accepted academic practice. No use, distribution or reproduction is permitted which does not comply with these terms. 